\title{
Lithostratigraphy, mineralogy and the boron-bearing brine evolution of DaQaidam Salt Lake in Qaidam Basin since Holocene period, northern Qinghai-Tibet Plateau
}

\author{
Chunliang Gao ${ }^{1,2^{*}}$, Junqing $\mathrm{Yu}^{1,2}$, Xiuyun $\mathrm{Min}^{1}$, Aiying Cheng ${ }^{1,2}$ \\ ${ }^{1}$ Key Laboratory of Comprehensive and Highly Efficient Utilization of Salt Lake Resources, Qinghai Institute of Salt Lakes, Chinese \\ Academy of Sciences, Xining, Qinghai, 810008, China \\ ${ }^{2}$ Qinghai Provincial Key Laboratory of Geology and Environment of Salt Lakes, Qinghai Institute of Salt Lakes, Chinese Academy of \\ Sciences, Xining, Qinghai, 810008, China
}

\begin{abstract}
Little attention has been paid to the study of sedimentary records from DaQaidam Salt Lake regarding brine evolution and hydro-climate change. Here we report the results of AMS ${ }^{14} \mathrm{C}$ dating and mineralogical investigation on a sediment profile D4 from the south central of perennial saline water-body. The result revealed that pinnoite deposit in the lakebed was formed in early Holocene, the lake underwent three stages of lake-level and brine evolution in Holocene period, which were determined mainly by precipitation-controlled catchment inflow. The mineralogical records also depicted fluctuations in lake level and hydrochemistry on decadal and centennial scales.
\end{abstract}

\section{Introduction}

DaQaidam Salt Lake is known for its both liquid and solid boron resource in Qaidam Basin, and the exploitation in DaQaidam Salt Lake had started since 1950s, related geological, geochemical and chemical studies focused on the distribution, sedimentary characteristics and material sources of borate minerals in onshore sites [1-4]. Especially, three cores were drilled and finally the pinnoite deposit was discovered for the first time from drill core $2^{\#}$ (about $700 \mathrm{~cm}$ in depth), and the chemical conditions of pinnoite deposit in the lakebed were discussed preliminarily [5]. However, little attention has been paid to the brine evolution and hydroclimate change correlated with the formation of pinnoite deposit [6-8]. Here we report the results of sediment profile D4 from DaQaidam Salt Lake in Qaidam Basin, including the lithostratigraphic and mineralogical records, as well as AMS ${ }^{14} \mathrm{C}$ dating. The study aims to discuss the brine evolution and hydro-climate change correlated with the formation of pinnoite deposit since Holocene period.

\section{Materials and methods}

\subsection{Sample descriptions}

The sediment profile D4 $\left(37^{\circ} 49^{\prime} 33^{\prime \prime} \mathrm{N}, 95^{\circ} 15^{\prime} 44^{\prime \prime} \mathrm{E}\right)$ was collected from the south central of DaQaidam Salt Lake (figure 1), and the depth is 735 centimeters. We sampled after the manual pumping and excavating, and the sampling resolution varied from 2 to $20 \mathrm{~cm}$ according to the sediment characteristics. One black muddy sample and all the sediment samples were selected from profile D4 prepared for AMS ${ }^{14} \mathrm{C}$ dating and XRD analysis, respectively. Finally, all the sediment samples were stored in cool rooms at $4{ }^{\circ} \mathrm{C}$.

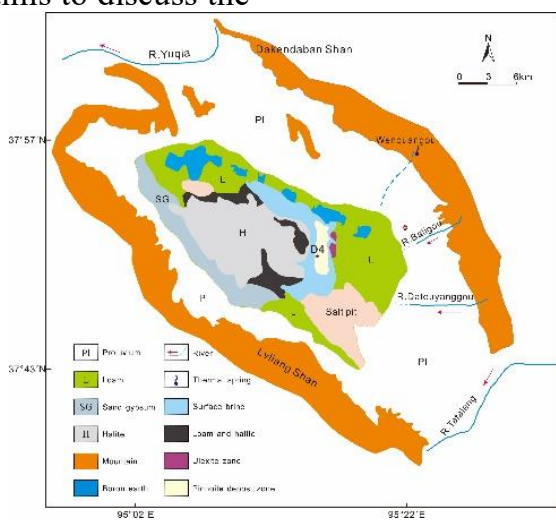

Figure 1. The map of DaQaidam Salt Lake in Qaidam Basin, showing the important geomorphologic features and the location of sediment profile D4.

*Corresponding author's e-mail: chunlianggao@isl.ac.cn 


\subsection{Analytical methods}

One bulk organic material for AMS ${ }^{14} \mathrm{C}$ dating were picked from the sediment profile D4 of DaQaidam Salt Lake, and the pretreatment followed by acid-alkali-acid processes [9]. Before AMS ${ }^{14} \mathrm{C}$ dating, the sample was gently crushed and dispersed in deionized water. Then, it washed with $2 \mathrm{~mol} / \mathrm{L}$ hot $\mathrm{HCl}$ acid to eliminate carbonates, followed by an alkali wash $(0.5 \mathrm{~mol} / \mathrm{L} \mathrm{NaOH})$ to remove secondary organic acids, a final acid rinse to neutralize the solution before drying. All samples were chemically pretreated, combusted and cryogenically purified in Beta Analytic Inc of Miami in the United States of America.

All samples for XRD analysis were air-dried at room temperature $\left(25^{\circ} \mathrm{C}\right)$, ground in a mortar and pestle, and passed through a $63 \mu \mathrm{m}$ sieve. Phillips X-pert Pro X-ray diffraction with $\mathrm{Cu} \mathrm{K \alpha}$ radiation $(\lambda=1.5406 \AA)$ at a scanning rate of $2^{\circ} \mathrm{min}^{-1}$ for $2 \theta$ ranging from $10^{\circ}$ to $80^{\circ}$. Mineral identification and concentration were estimated from the bulk mineral diffractograms, using the intensity of the strongest peak for each mineral with an automated searchmatch computer program X-Pert HighScore Plus. Duplicate analyses of mineralogy for 20 samples in

Table 1. AMS ${ }^{14} \mathrm{C}$ age, the reservoir-effect calibrated age and the calibrated calendar age from sediment profile D4 in DaQaidam Salt Lake.

\begin{tabular}{lcccccc}
\hline Laboratory ID & $\begin{array}{c}\text { Depth } \\
(\mathrm{cm})\end{array}$ & $\begin{array}{c}\text { Material } \\
\text { dated }\end{array}$ & $\begin{array}{c}{ }^{14} \mathrm{C} \text { age } \\
(\mathrm{yr} \mathrm{BP})\end{array}$ & $\begin{array}{c}\text { Calibrated age } \\
(\mathrm{yr} \mathrm{BP})\end{array}$ & $\begin{array}{c}\text { Calendar age } \\
(\text { cal yr BP })\end{array}$ \\
\hline \multirow{2}{*}{ Beta-467195 } & $533-540$ & TOC & $10370 \pm 30$ & $8570 \pm 30$ & 9498 & (9529) 9554
\end{tabular}

\subsection{Mineralogical and lithostratigraphic records}

The sediment profile D4 is located in the south central of DaQaidam Salt Lake (figure 1), pinnoite deposits ranged from 549 to $735 \mathrm{~cm}$, and the sediments above $549 \mathrm{~cm}$ represented a series of successive sedimentary sequence in perennial water-body since early Holocene. More 70 samples from profile D4 were determined by XRD analysis, The main saline minerals are composed of, on average, $29.1 \%$ carbonate (calcite, aragonite, dolomite and hydromagnesite), $16.0 \%$ gypsum, and $15.4 \%$ halite. The detrital components include, on average, $15.6 \%$ quartz, $6.6 \%$ chlorite, $4.4 \%$ muscovite and $3.8 \%$ albite. Within the detecting limit of XRD analysis, pinnoite ore is the only borate mineral detected from sediment profile D4 of DaQaidam Salt Lake.

\subsubsection{Evaporite minerals}

Evaporite minerals can be used as effective proxy records to interpret the paleoclimatic and paleoenvironmental changes. The compositions of authigenic evaporite different lithostratigraphic units, indicated that the error of mineralogical data is approximately $\pm 5 \%$. The experiment was conducted at Qinghai Institute of Salt Lakes, Chinese Academy of Sciences, China.

\section{Results and discussion}

\subsection{AMS ${ }^{14} \mathrm{C}$ chronology}

The sediments of DaQaidam Salt Lake are mainly evaporitic minerals, so no suitable samples with sufficient amount of organic matter for radiocarbon measurement. Fortunately, only one bulk organic material for $\mathrm{AMS}{ }^{14} \mathrm{C}$ dating were picked from the sediment profile D4 of DaQaidam Salt Lake. In addition, the sediment profiles D2 and D4 are in the same deposition system of DaQaidam Salt Lake, we obtained the ${ }^{14} \mathrm{C}$ reservoir-effect value of profile $\mathrm{D} 2$ in previous study [6]. Therefore, As shown in Table 1, the AMS ${ }^{14} \mathrm{C}$ age, the reservoir-effect calibrated age and the calibrated calendar age of sediment profile D4 was obtained from DaQaidam Salt Lake in Qaidam Basin. The calendar age was transformed by IntCal13 calibration curve procedure [10]. 


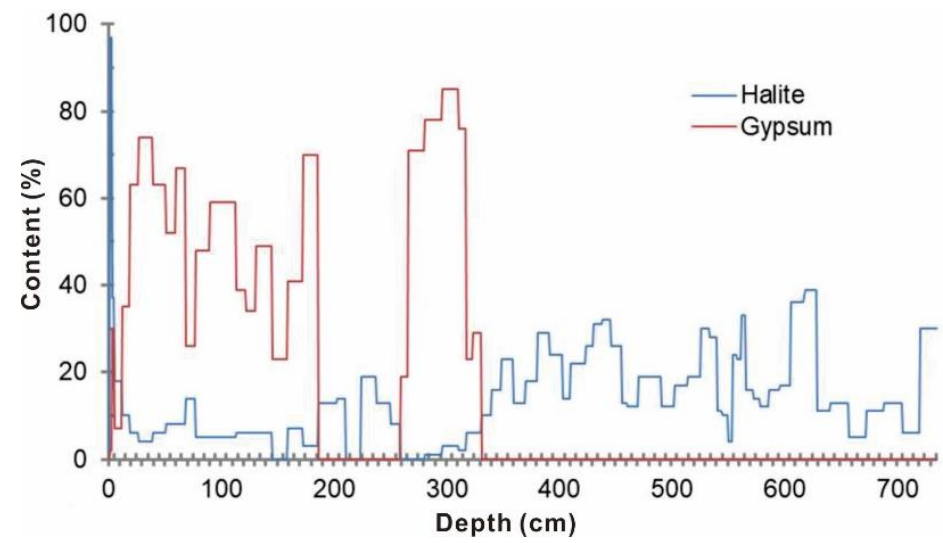

Figure 2. The gypsum and halite compositions from sediment profile D4 in DaQaidam Salt Lake.

\subsubsection{Carbonate minerals}

The crystalline precipitation of carbonate in the waterbody is mainly controlled by the $\mathrm{Mg} / \mathrm{Ca}$ ratio. The calcite began to precipitation when the water contained a small amount of $\mathrm{Mg}^{2+}$, and the aragonite precipitated when the concentration of $\mathrm{Mg}^{2+}$ increased. When the $\mathrm{Mg} / \mathrm{Ca}$ ratio is relatively higher, the high-magnesium calcite can be crystallized. Only under the condition of higher $\mathrm{Mg} / \mathrm{Ca}$ ratio, higher temperature and slower crystallization rate, the dolomite with standardized compositions and high

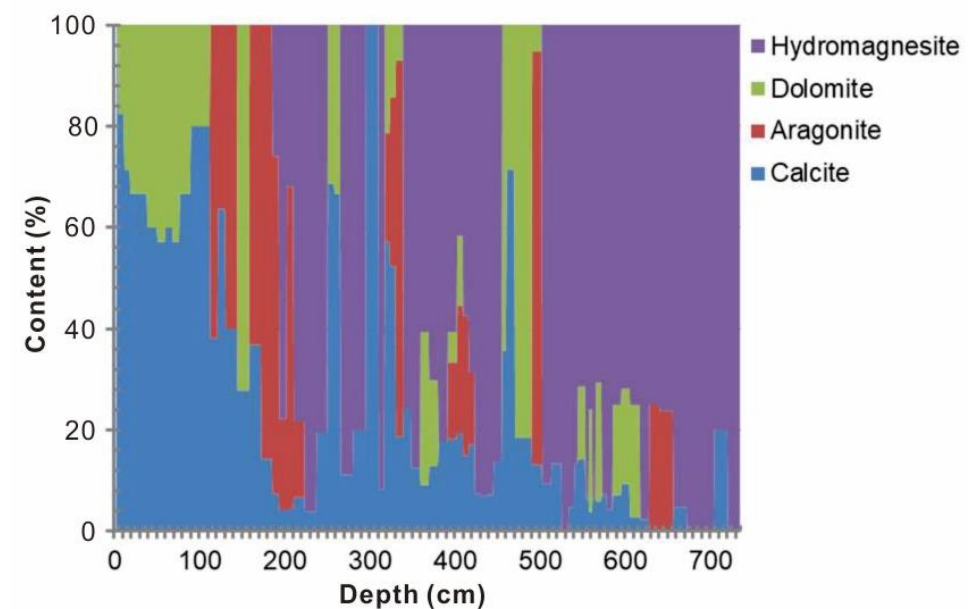

Figure 3. The carbonate compositions from sediment profile D4 in DaQaidam Salt Lake.

\subsubsection{Detrital minerals}

The detrital mineral content in lacustrine sediment indicated the change of lake water inflow and hydrodynamic conditions. In general, the relatively higher detrital content indicated that more lake water degree of order was formed. Finally, with the evolution of lake water, when the $\mathrm{Mg} / \mathrm{Ca}$ ratio reached 20-30 with the $\mathrm{pH}$ value increasing to 9.1, the hydromagnesite precipitated [11].

XRD results showed that the carbonate minerals in the sediment profile D4 are mainly composed of calcite, aragonite, dolomite and hydromagnesite (figure 3). Except calcite, other three carbonate minerals such as aragonite, dolomite and hydromagnesite fluctuated frequently and abruptly.

inflow with higher water level, and the lake was in the desalination phase, and vice versa.

The quartz and clay mineral content reached $42 \%$ and $22 \%$ ranged from 251 to $258 \mathrm{~cm}$ in the profile, respectively, which reflected the period of higher lake water inflow and lower brine salinity. In addition, the quartz and clay mineral content displayed the similar variation trend (figure 4). 


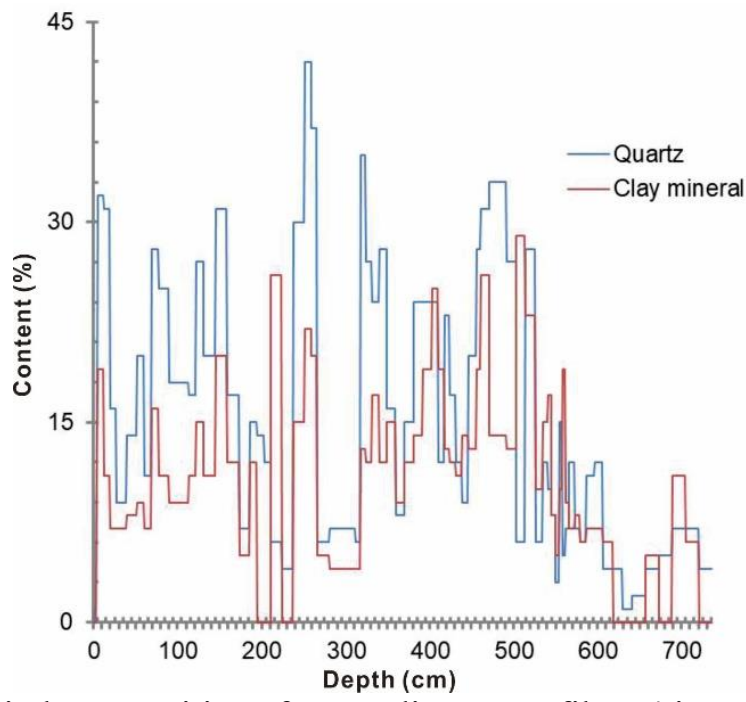

Figure 4. The detrital compositions from sediment profile D4 in DaQaidam Salt Lake.

\subsubsection{Pinnoite mineral}

XRD results showed that the main components of pinnoite deposit from sediemnt profile D4 are pinnoite, hydromagnesite, halite and detrital

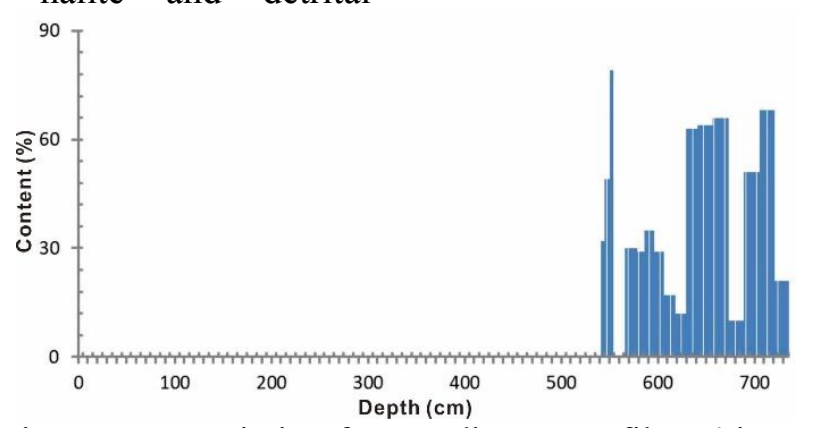

Figure 5. The pinnoite content variation from sediment profile D4 in DaQaidam Salt Lake.

According to the sediment characteristics and mineral compositions of profile D4 from DaQaidam Salt Lake, the lithostratigraphic sequence can be divided into four sedimentation units from bottom to top, as follows:

Unit I $(735-541 \mathrm{~cm})$ is the basal sediment, which is characterized by massive pinnoite deposit, with an average value of $38.3 \%$ pinnoite and no more than $16 \%$ $\mathrm{B}_{2} \mathrm{O}_{3}$ content.

Unit II $(541-331 \mathrm{~cm})$ is characterized by interbedded layer of black grey salt-bearing silty mud and black nodule with the lithology and mineral compositions changed. The gypsum mineral disappeared abruptly, hydromagnesite, calcite and halite contents were relatively stable, and clay mineral and quartz contents increased abruptly.

Unit III $(331-186 \mathrm{~cm})$ is characterized by grey saltbearing silty mud. The gypsum and hydromagnesite content fluctuated frequently, the halite and calcite contents decreased, but clay mineral and quartz contents reached up to the maximum.

Unit IV $(186-0 \mathrm{~cm})$ is characterized by interbedded layer of earth yellow evaporite and black grey saltbearing mud. Compared to unit III, the gypsum content increased obviously, and the halite and calcite contents were relatively stable, but clay mineral and quartz minerals (figure 5). The characteristics of laminated pinnoite ore layer enriched in $29.1 \%$ hydromagnesite, suggesting that the paleo-lake level went down seasonally to near-dry conditions due to the intense evaporation and concentration effect [7].

\begin{abstract}
contents decreased to some extent. Especially, hydromagnesite mineral disappeared abruptly.
\end{abstract}

\subsection{Brine evolution and hydro-climate change}

AMS ${ }^{14} \mathrm{C}$ chronological results demonstrated that the pinnoite deposit in unit I of sediment profile D4 formed in the early Holocene period. It is estimated that boron content in brine when pinnoite deposit formed was at least equivalent to the modern brine, what is more, the pinnoite deposit would reduce the boron content in original brine. Thus, we concluded that the boron content reached up to $600 \mathrm{mg} / \mathrm{L}$ in modern brine just due to the no considerable amount of boron minerals been formed, and the boron content in brine enriched and concentrated steadily including accumulation in original brine.

Compared to unit I, the mineral compositions as well as sedimentary structure illustrated that the lake water flowed into DaQaidam Salt Lake dereased in unit II after borate deposit formed, and lake level was relatively shallower with higher salinity.

In addition, increasing clay mineral and obviously decreasing saline nodule as the main characteristics in unit III, with the gypsum content fluctuated frequently, suggesting the water depth and inflow increased to some 
extent. With the increasing clay mineral content, TOC content obviously increased with a small quantity of dolomite. Dolomite is generally related with enhanced reducibility in lakebed environment [12], and the carbonate content maybe controlled by $\mathrm{Mg} / \mathrm{Ca}$ ratio in brine. Compared with the II phase, lithostratigraphic characteristics and mineralogical evidence mentioned above illustrated that the lake brine area expanded a lot in the III phase.

The sedimentary structure of unit IV is completely different from units III and II, reflecting more frequent dilution-salinization fluctuation and water level higherlower alternation on decadal to centennial scales in lake region. In general, the lake region had been moving towards aridification with relative higher brine salinity and lower lake level since late Holocene period.

\section{Conclusions}

After pinnoite deposit formed in the lakebed since Holocene period, the hydrochemical type of surface brine unchanged, and the hydrochemistry on seasonal, decadal, centennial and millennial scales were controlled by the precipitation in mountainous area. Especially, the considerable amount of boron minerals had not been formed, boron content in brine enriched and concentrated.

Since Holocene period, the lake sediment displayed three different sedimentary environment, as follows: pinnoite deposit dominated in the early phase with relatively shallower paleo-lake water level and higher brine salinity; the salt-bearing mud deposit as the main characteristics in the middle phase with relatively deeper water level and stronger reducibility; the interbedded layer of evaporite and salt-bearing mud as the sedimentary characteristics showed that intensive fluctuation of lake water inflow on decadal scales for the past several thousand years in late Holocene period.

\section{Acknowledgments}

We thank Bo Yang ang Li Han for laboratory assistance, Rongchang Hong for assistance with fieldwork. This work was supported by the National Natural Science Foundation of China (41501052, U1407206, 41471013), Qinghai Natural Science Foundation of China (2017-ZJ928Q), the Second Tibetan Plateau Scientific Expedition and Research Program (2019QZKK0805) and Thousand Talents Plan of Qinghai Province (Grant to XY Min).

\section{References}

1. Yang, Q. (1983) The geological survey of DaQaidam and XiaoQaidam salt lakes in Qaidam Basin, Qinghai province. Qinghai Geol., 3: 38-63.

2. Zhang, P.X., Chen, K.Z., Yu, S.S. (1987) Salt Lakes in Qaidam Basin. Science Press, Beijing.

3. Zheng, M.P., Xiang, J., Wei, X.J., Zheng, Yuan. (1989) Salt Lakes on Qinghai-Xizang Plateau. Beijing Science and Technology Press, Beijing.
4. Gao, S.Y., Song, P.S., Xia, S.P., Zheng, M.P. (2007) Salt lake chemistry - new type boron and lithium salt lakes. Science Press, Beijing.

5. Liu, D.G., Gao, S.Y. (1995) Discovery of pinnoite from the deposit of DaQaidam Salt Lake. J. Salt Lake Res., 3: 1-9.

6. Gao, C.L., Zhang, L.S., Yu, J.Q., Cheng, A.Y., Liu, Y. (2011) A mineralogical record of brine evolution and environmental change from DaQaidam Salt Lake in the northern Qaidam Basin. Geochim., 40: 156-162.

7. Yu, J.Q., Hong, R.C., Gao, C.L., Cheng, A.Y., Zhang, L.S. (2018) Pinnoite deposit in DaQaidam saline lake, Qaidam Basin, China: hydroclimatic, sedimentologic, and geochemical constraints. Minerals, 8: 258.

8. Gao, C.L., Yu, J.Q., Min, X.Y., Cheng, A.Y., Hong, R.C., Zhang, L.S., Li, T.W. (2019) The sedimentary evolution of Da Qaidam Salt Lake in Qaidam Basin, northern Tibetan Plateau: implications for hydro-climate change and the formation of pinnoite deposit. Environ. Earth Sci., 78: 463

9. Van Klinken, G.J., Hedges, G.E.M. (1998) Chemistry strategies for organic ${ }^{14} \mathrm{C}$ samples. Radiocarbon, 40: 51-56.

10. Reimer, P.J., Bard, E., Bayliss, A., Beck, J.W., Blackwell, P.G., Ramsey, B.C., Buck, C.E., Cheng, H., Edwards, R.L., Friedrich, M., Grootes, P.M., Guilderson, T.P., Haflidason, H., Hajdas, I., Hatté, C., Heaton, T.J., Hogg, A.G., Hughen, K.A., Kaiser, K.F., Kromer, B., Manning, S.W., Niu, M., Reimer, R.W., Richards, D.A., Scott, E.M., Southon, J.R., Turney, C.S.M., Van der Plicht, J. (2013) IntCal13 and MARINE13 radiocarbon age calibration curves 0-50000 years cal BP. Radiocarbon, 55: 1869-1887.

11. Alderman, A.R. (1965) Dolomitic sediments and their environment in the South-East of South Australia. Geochim. Cosmochim. Ac., 29: 13551365.

12. Yu, J.Q., Zhang, L.S. (2008) LAKE QINGHAI: Paleoenvironment and Paleoclimate. Science Press, Beijing. 